\title{
PENGARUH LAMA PERENDAMAN DALAM LARUTAN NATRIUM METABISULFIT TERHADAP KARAKTERISTIK TEPUNG LABU KUNING
}

(The Effect of soaking time in sodium metabisulfite solution on the characteristics of pumpkin flour)

\author{
Ulfa Reza ${ }^{1}$, Bambang Sukarno Putra ${ }^{1}$, Diswandi Nurba ${ }^{{ }^{*}}$ \\ ${ }^{1}$ Program Studi Teknik Pertanian, Fakultas Pertanian, Universitas Syiah Kuala \\ *Corresponding author : diswandinurba@unsyiah.ac.id
}

\begin{abstract}
Abstrak. Tujuan penelitian ini adalah untuk mengetahui karakteristik tepung labu kuning. Parameter penelitian meliputi rendemen, kadar air, derajat keasaman $(\mathrm{pH})$, kadar pati, uji organoleptik hedonik warna dan aroma. Data di analisa menggunakan ANOVA dan excel. Hasil penelitian menunjukkan nilai rata-rata rendemen tepung labu kuning tertinggi terdapat pada perlakuan 0 menit yaitu $11,33 \%$, nilai rata-rata kadar air tepung labu kuning tertinggi terdapat pada perlakuan 60 menit yaitu $9,33 \%$, nilai rata-rata derajat keasaman $(\mathrm{pH})$ tertinggi terdapat pada perlakuan 0 menit yaitu 6,79 , nilai rata-rata kadar pati tertinggi terdapat pada perlakuan 40 menit yaitu $72,95 \%$, nilai rata-rata uji organoleptik hedonik warna tertinggi terdapat pada perlakuan 60 menit yaitu 4,20 dengan skor 4 (suka), nilai rata-rata uji organoleptik hedonik aroma tertinggi terdapat pada perlakuan 0 menit yaitu 3,71 dengan skor 4 (suka).
\end{abstract}

Kata Kunci: Lama perendaman, Labu Kuning, Natrium Metabisulfit, ANOVA

Abstract. The purpose of this study was to determine the characteristics of pumpkin flour. The research parameters included yield, moisture content, acidity $(\mathrm{pH})$, starch content, hedonic organoleptic color and aroma test. Data was analyzed using ANOVA and Excel. The results showed that the highest yield of pumpkin flour was at 0 minutes treatment which was $11.33 \%$, the highest average value of water content of pumpkin flour was at 40 minutes treatment which was $9.33 \%$, the average value of acidity degree $(\mathrm{pH})$ is highest in 0 minute treatment, which is 6,793 , the highest average value of starch is found in 40 minutes treatment which is $72.95 \%$, the highest average hedonic organoleptic test value is found in 60 minutes treatment which is 4,20 with a score 4 (likes), the highest average hedonic organoleptic test score was found at 0 minutes treatment which was 3.71 with a score 4 (likes).

Keywords :Soaking Time, Pumpkin, Sodium Metabisulfite, ANOVA

\section{PENDAHULUAN}

Labu kuning adalah jenis jenis buah yang tidak mudah rusak hal ini dipengaruhi oleh kulit yang tebal dan keras sehingga dapat menghambat laju respirasi. Maka dari itu labu kuning lebih awet atau tahan lama dibandingkan buah lainnya. Labu kuning dapat disimpan sampai dengan enam bulan bisa juga lebih, tergantung dengan cara penyimpanannya. Di pasaran sering dijual dalam bentuk irisan. Labu kuning yang telah diiris akan mudah membusuk atau tidak taham lama dibandingkan dengan buah yang masih utuh maka dari itu harus memikirkan cara pengolahan agar daya simpan bisa lebih lama, maka dari itu labu kuning dapat diolah menjadi tepung.

Pengolahan labu kuning menjadi tepung merupakan salah satu upaya pengawetan labu tanah untuk memperpanjang masa simpan serta merupakan upaya peningkatan daya guna dari labu tanah agar dapat dimamfaatkan sebagai bahan baku industri pangan. Dimana proses dari penepungan labu tanah meliputi pembersihan, pengeringan, penggilingan dan pengayakan. Peranan dari proses penepungan labu kuning ini dapat digunakan sebagai penunjang dari penggunaan tepung terigu yang semakin meningkat.

Pada proses pembuatan tepung labu kuning sering terjadinya masalah pada bhan yaitu terjadi browning atau proses pencoklatan pada bahan. Maka dapat berpengaruh terhadap tepung yang dihasilkan maka warna tepung akan lebih coklat daya minat masyarakatpun berkurang. Proses 
pencoklatan pada tepung labu kuning terjadi karena adanya proses pemanasan dimana asam amino akan bereaksi ditambah dengan adanya gula pereduksi didalam bahan. Sehingga membentuk melanoidin yang bewarna coklat. Cara agar mencegah terjadinya browning atau perubahan warna pada tepung labu kuning dapat dilakukan perlakuan pendahulan terlebih dahulu dengan cara direndam dengan larutan natrium metabisulfit.

\section{METODOLOGI PENELITIAN}

\subsection{Tempat dan Waktu Penelitian}

Penelitian ini dilaksanakan di Laboratorium Pasca Panen, Program Studi Teknik Pertanian, Fakultas Pertanian, Universitas Syiah Kuala. Waktu Penelitian dilaksanakan pada bulan Agustus sampai dengan Oktober 2018.

\subsection{Alat}

Alat yang digunakan pada penelitian ini adalah pisau, telenan, baskom, grinder, tray drayer, ayakan 80 mesh merek Retsch $\mathrm{GmbH}$, timbangan analitik merek kern ${ }_{\mathrm{EG}}$, benchtop pH meter merek AZ 86505, cawan petri, slicer dan gelas ukur. Bahan yang akan digunakan dalam penelitian ini adalah labu kuning, larutan natrium metabisulfit 1500 ppm dan aquades.

\subsection{Prosedur Penelitian}

Penelitian ini dimulai dengan mempersiapkan semua alat dan bahan yang diperlukan. Tahap pertama dengan mensortasi labu kuning, kemudian dipusan kulitnya menggunakan pisau. Labu kuning yang telah dikupas lalu ditimang sebanyak 600 gr untuk tiap-tiap perlakuan, lalu dirajang menggunakan slicer dan dimasukkan kedalam larutan natrium metabisulfit dengan konsenterasi 1500 ppm dengan variasi perendaman yaitu $0,20,40$, dan 60 menit. Selanjutnya bahan yang telah direndam di keringkan menggunakan tray drayer dengan suhu $55^{\circ} \mathrm{C}$ sampai kondisi bahan rapuh dan mudah dipatahkan dengan kadar air 13\%. Kemudian dilakukan pengalusan bahan menggunakan grinder sampai halus lalu diayak menggunakan ayakan 80 mesh. Hasil penggilingan dimasukkan kedalam toples langsung agar tidak terjadi kontaminasi benda asing, lalu dilakukan analisis rendemen, kadar air, derajat keasaman $(\mathrm{pH})$, kadar pati, uji organoleptik hedonik warna dan aroma.

\section{HASIL DAN PEMBAHASAN}

\section{Rendemen Tepung Labu Kuning}

Pada Gambar 1 dapat dilihat rendemen dari tepung labu kuning berdasarkan perlakuan lama perendaman dalam suatu natrium metabisulfit $1500 \mathrm{ppm}$.

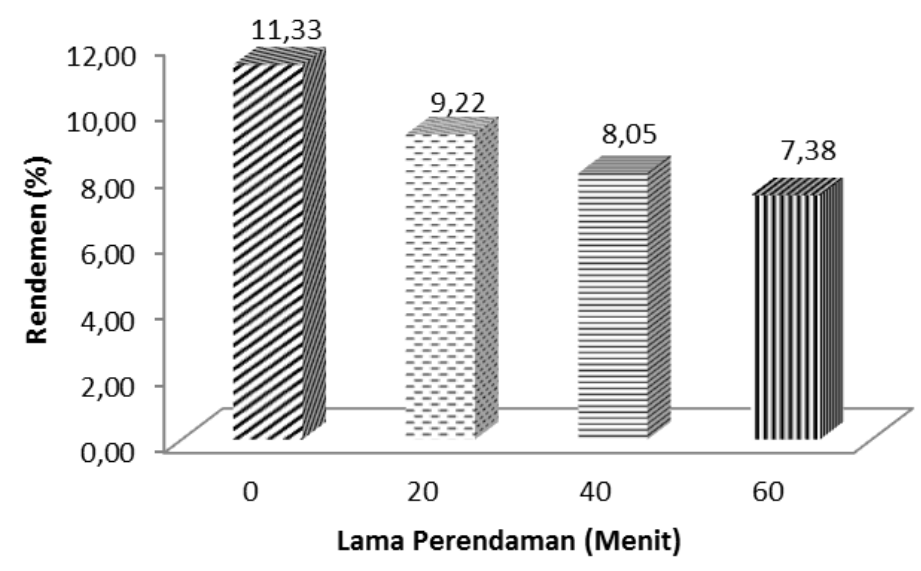

Gambar 1. Rendemen tepung labu kuning dengan variasi lama perendaman Menggunakan larutan natrium metabisulfit $1500 \mathrm{ppm}$ 
Dari Gambar 1 dapat kita lihat nilai rata-rata rendemen tepung labu kuning tertinggi terdapat pada perlakuan 0 menit yaitu $11,33 \%$, sedangkan rata-rata rendemen terendah terdapat pada perlakuan 60 menit dengan nilai 7,38\%. dengan demikian bahwa semakin lama labu kuning direndam menggunakan larutan natrium metabisulfit maka hasil dari rendemen juga semakin rendah hal ini disebabkan karena bahan yang terlalu lama direndam maka kandungan air pada labu kuning beserta komponen-komponen lain yang terkandung dalam labu kuning akan larut dalam air rendaman oleh karena itu akan terikat oleh sulfit sehingga mengakibatkan kandungan air dalam bahan dan komponen-komponen lain yang larut dalam air rendaman akan ikut menguap pada saat proses pengeringan bahan menggunakan tray dryer yang berlangsung selama 23 jam dan rendemen tepung yang dihasilkan akan semakin menurun. Dari nilai ANOVA rendemen bahwa lama perendaman dalam perendaman dalam natrium metabisulfit $1500 \mathrm{ppm}$ berpengaruh tidak nyata hal ini dikarenakan bahwa nilai signifikan $>$ dari 0,05 terhadap nilai rendemen tepung labu kuning sehingga tidak prlu dilakukan uji lanjut.

\section{Kadar Air Tepung Labu Kuning}

Pada Gambar 2 dapat dilihat rendemen dari tepung labu kuning berdasarkan perlakuan lama perendaman dalam suatu natrium metabisulfit $1500 \mathrm{ppm}$.

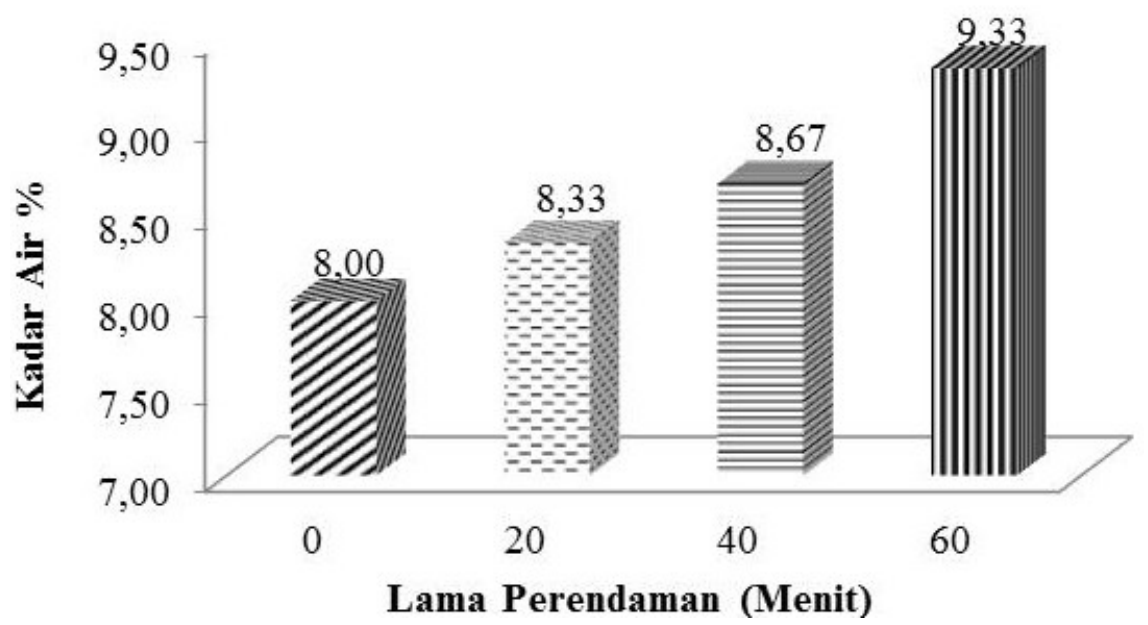

Gambar 2. Kadar air tepung labu kuning dengan variasi lama perendaman menggunakan larutan natrium metabisulfit $1500 \mathrm{ppm}$

Dari Gambar 2 dapat kita lihat bahwa nilai rata-rata kadar air pada tepung labu kuning tertinggi diperoleh pada lama perendaman 60 menit yaitu 9,33\% sedangkan kadar air terendah diperoleh dari lama perendaman 0 menit dengan nilai rata-rata $8 \%$. Dari hasil analis sidik ragam terhadap kadar air yang menjelaskan bahwasanya lama perendaman dalam larutan natrium metabisulfit $1500 \mathrm{ppm}$ berpengaruh tidak nyata hal ini dikarenakan nilai signifikan $>$ dari 0,05 terhadap kadar air tepung labu kuning sehingga tidak perlu dilakukan uji lanjut.

Semakin tinggi kadar air yang terkandung didalam tepung tersebut maka dapat mempercepat proses kerusakan karena pertumbuhan mikroorganisme semakin cepat berkembang. Hal ini sesuai dengan pernyataan Winarto (2002) jika kadar air semakin rendah maka akan dapat melambatkan pertumbuhan mikroorganisme yang berkembang baik pada bahan sehingga proses pembusukan akan berlangsung lama. Apabila suatu bahan direndam dalam larutan natrium metabisulfit akan mengakibatkan air yang masuk dalam suatu bahan lebih banyak sehingga kadar airnya semakin meningkat. Ini sesuai dengan pernyataan Winarto (2002) semakin lama waktu perendaman dalam larurutan natrium metabisulfit kadar air yang terserap pada bahan semakin banyak. 
Berdasarkan SNI 3751:2009 kadar air tepung terigu yang telah ditetapkan oleh BSN yaitu dibawah $14 \%$ nilai rata-rata kadar air tepung labu kuning yaitu 8,58\% maka kadar air tepung labu kuning pada penelitian ini telah memenuhin standar tepung. Sesuai dengan pernyataan Dewi (2017) apa bila kadar air dibawah 14\% adalah kadar air yang sesuai untuk produk pangan karena kadar air yang tinggi pada suatu bahan pangan cenderung akan mengalami kerusakan lebih cepat dibandingankan dengan bahan pangan memiliki kadar air yang lebih rendah.

\section{Derajat Keasaman (pH) Tepung Labu Kuning}

Pada Gambar 3 dapat dilihat rendemen dari tepung labu kuning berdasarkan perlakuan lama perendaman dalam natrium metabisulfit $1500 \mathrm{ppm}$.

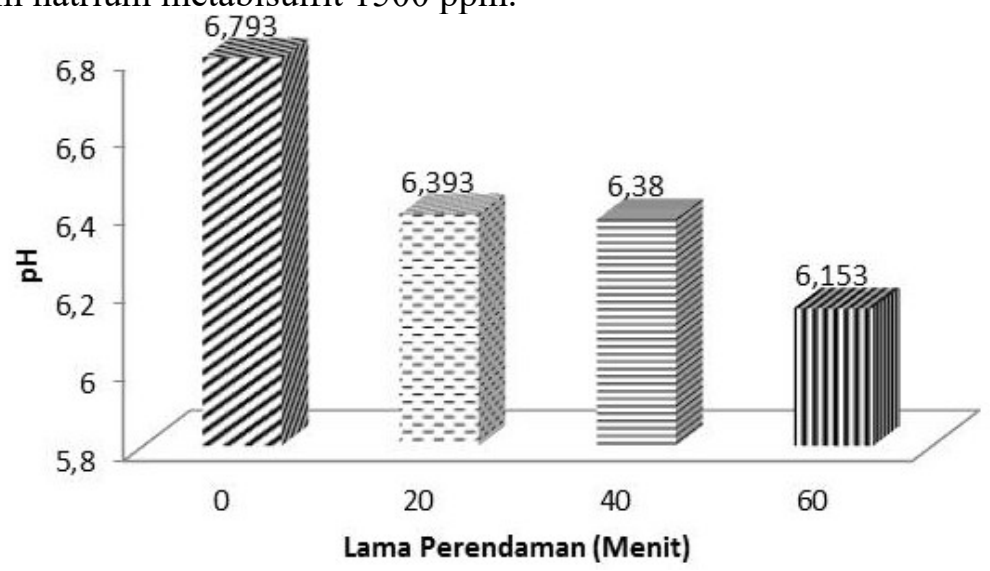

Gambar 3. Kandungan $\mathrm{pH}$ tepung labu kuning dengan variasi lama perendaman menggunakan larutan natrium metabisulfit $1500 \mathrm{ppm}$

Dari Gambar 3 dapat dilihat bahwasanya nilai rata-rata derajat keasaman $(\mathrm{pH})$ pada tepung labu kuning tertinggi diperoleh pada lama perendaman 0 menit yaitu 6,793 sedangkan derajat kesaman $(\mathrm{pH})$ terendah diperoleh dari lama perendaman 60 menit dengan nilai rata-rata 6,153. Dari hasil analis sidik ragam (ANOVA) terhadap derajat kesaman $(\mathrm{pH})$ yang menjelaskan bahwa lama perendaman dalam larutan natrium metabisulfit $1500 \mathrm{ppm}$ dapat berpengaruh nyata hal ini dikarenakan nilai signifikan $<$ dari 0,05 terhadap kadar air tepung labu kuning sehingga perlu dilakukan uji lanjut.

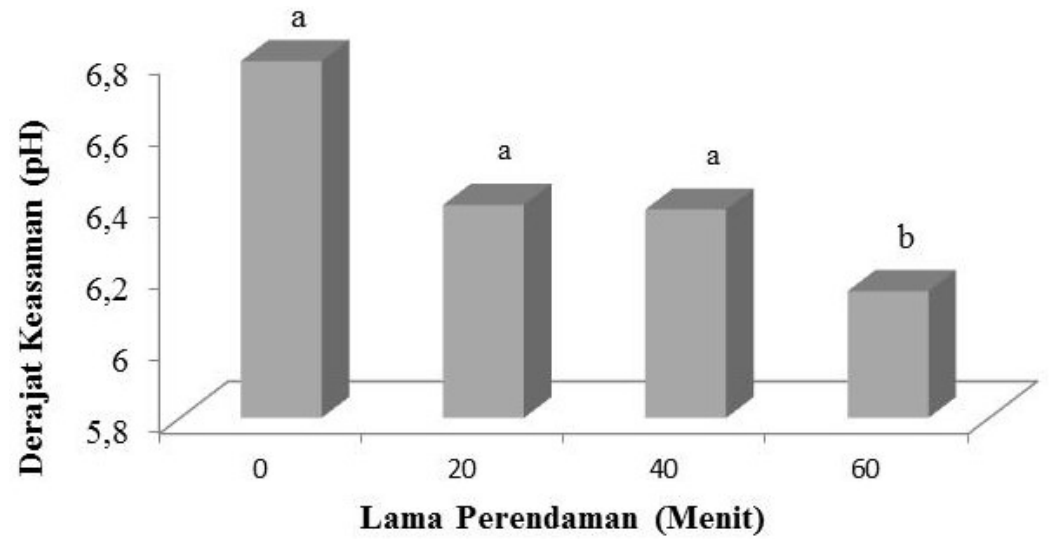

Gambar 4. Uji lanjut BNJ terhadap $\mathrm{pH}$ tepung labu kuning dengan variasi lama perendaman menggunakan larutan natrium metabisulsit metabisulfit $1500 \mathrm{ppm}$ 
Dari Gambar 4 dapat kita lihat bahwa hasil dari uji lanjut BNJ terhadap kandungan $\mathrm{pH}$ pada tepung labu kuning yaitu perlakuan lama perendaman 0 menit berbeda nyata terhadap perlakuan 20 dan 40 menit, perlakuan 0 menit juga berbeda nyata terhadap perlakuan lama perendaman 60 menit maka dari hasil tersebut dapat dikatakan bahwasanya pada perlakuan yang baik yaitu tanpa perendaman dalam larutan natrium metabisulfit $1500 \mathrm{ppm}$. Nilai $\mathrm{pH}$ pada tepung labu kuning berada pada kisaran yang tergolong aman untuk bahan pangan pertanian karena masih tergolong katagori basa yaitu berkisar antara 6,793-6,153. Hal tersebut esuai dengan pendapat Montolalu., dkk (2013) yang menyatakan bahwa sesuai Standarisasi Nasional Indonesia nilai $\mathrm{pH}$ pangan berkisar antara 6 sampai 7.

\section{Kadar Pati Tepung Labu Kuning}

Pada Gambar 5 dapat dilihat rendemen dari tepung labu kuning berdasarkan perlakuan lama perendaman dalam natrium metabisulfit $1500 \mathrm{ppm}$.

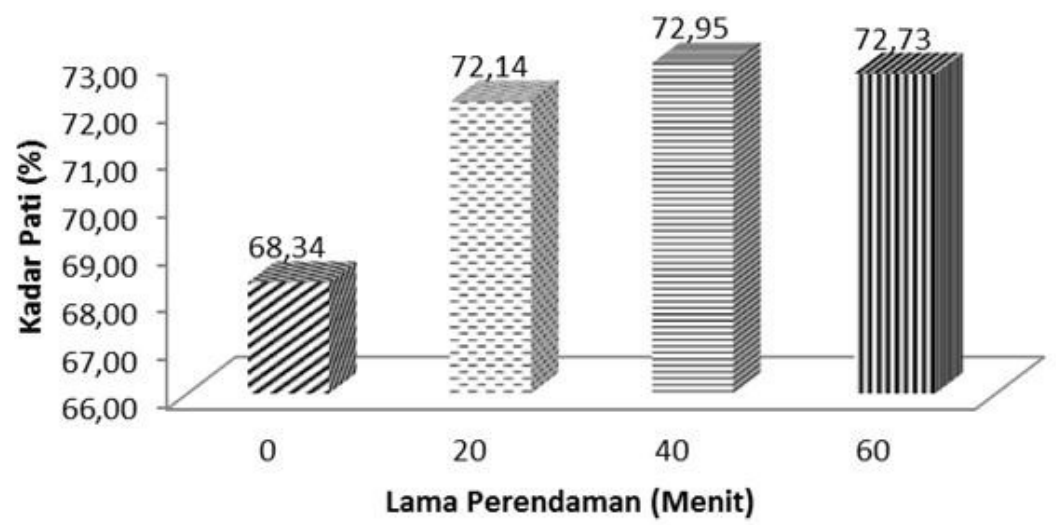

Gambar 5. Kandungan $\mathrm{pH}$ tepung labu kuning dengan variasi lama perendaman menggunakan larutan natrium metabisulfit $1500 \mathrm{ppm}$

Dari Gambar 5 kita lihat bahwa nilai rata-rata kadar pati pada tepung labu kuning tertinggi diperoleh pada lama perendaman 40 menit yaitu 72,95 sedangkan kadar pati terendah diperoleh dari lama perendaman 0 menit dengan nilai rata-rata 68,33. Kandungan pati yang tinggi disebabkan oleh karakteristik pati yang tidak larut dalam air. Dari hasil analis sidik ragam (ANOVA) terhadap kadar pati yang menjelaskan bahwasanya lama perendaman dalam larutan natrium metabisulfit $1500 \mathrm{ppm}$ berpengaruh nyata hal ini dikarenakan nilai signifikan $<$ dari 0,05 terhadap kadar pati tepung labu kuning sehingga perlu dilakukan uji lanjut. Uji lanjut BNJ dapat dilihat pada gambar 6. semakin lama waktu pada perendaman maka semakin banyak pati yang terhidrolisa sehingga kelarutannya semakin tinggi (Prabowo, 2010). 


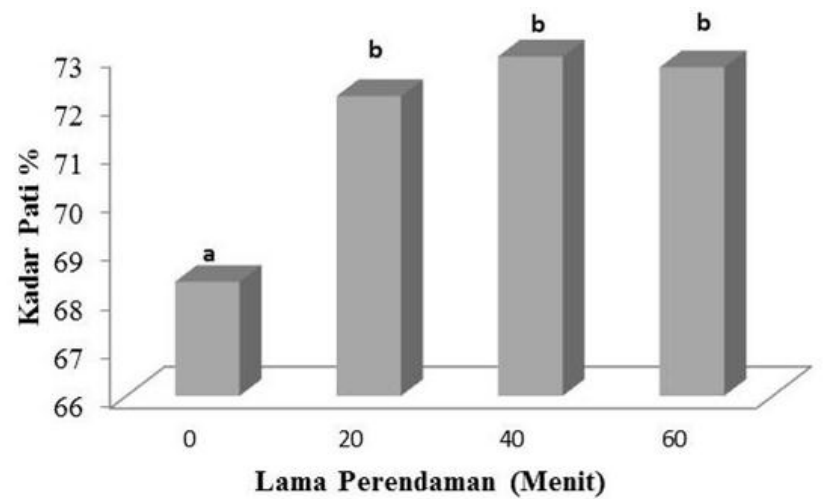

Gambar 6. Uji lanjut BNJ terhadap kadar pati tepung labu kuning dengan variasi lama perendaman menggunakan larutan natrium metabisulsit metabisulfit $1500 \mathrm{ppm}$

Dari Gambar 6 dapat kita lihat bahwa hasil uji BNJ terhadap kadar pati tepung labu kuning pada perlakuan 0 menit berbeda nyata terhadap perlakuan lama perendaman 20 menit dan 40 menit, perlakuan 0 menit juga berpengaruh nyata dengan perlakuan 60 menit sehingga dapat diambil kesimpulan bahwa perlakuan terbaik untuk kadar pati adalah pada lama perendaman 40 menit dengan nilai kadar patinya $72,95 \%$ dalam larutan natrium metabisulfit $1500 \mathrm{ppm}$.

\section{Uji Organoleptik Hedonik Tepung Labu Kuning}

\section{Organoleptik Hedonik Warna}

Pada Gambar 7 dapat dilihat uji organoleptik hedonik warna tepung labu kuning berdasarkan perlakuan lama perendaman dalam natrium metabisulfit $1500 \mathrm{ppm}$.

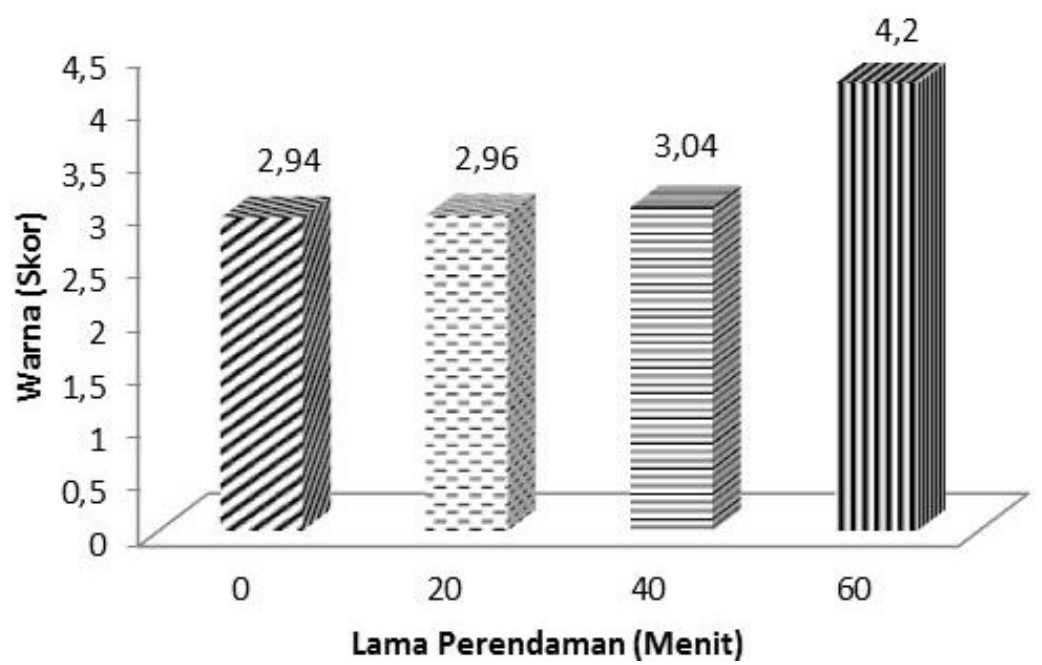

Gambar 7. Skor kesukaan terhadap warna tepung labu kuning dengan variasi lama perendaman menggunakan larutan natrium metabisulf $1500 \mathrm{ppm}$

Dari hasil uji organoleptik terhadap kesukaan warna pada Gambar 7 menunjukkan bahwa skor tertinggi atau yang paling disukai oleh panelis diperoleh dari lama perendaman 60 menit dengan nilai rata-rata 4,20 dengan skor 4 (suka), dan hasil uji organoleptik terhadap kesukaan warna menunjukkan skor terendah diperoleh dari lama perendaman 0 menit dengan nilai rata-rata 2,94 dengan nilai skor netral (3). Dari hasil analis sidik ragam (ANOVA) terhadap kadar air yang 
menjelaskan bahwasabya lama perendaman dalam larutan natrium metabisulfit $1500 \mathrm{ppm}$ dapat berpengaruh nyata hal ini dikarenakan nilai signifikan $<$ dari 0,05 terhadap kadar air tepung labu kuning sehingga perlu dilakukan uji lanjut.

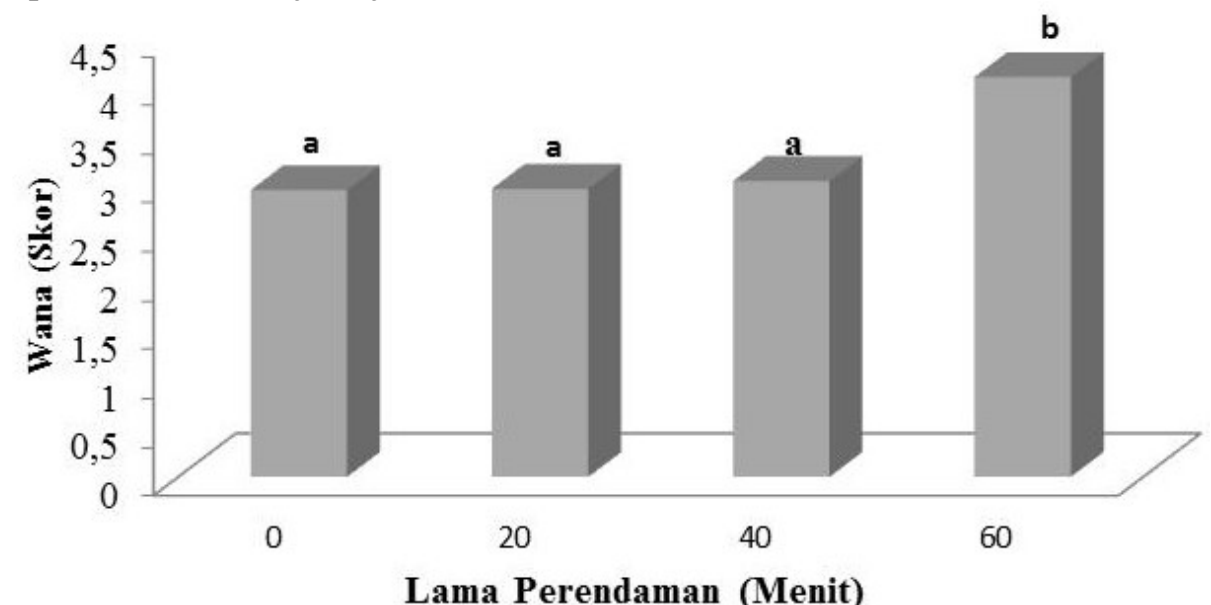

Gambar 8. Uji lanjut BNJ terhadap skor kesukaan warna tepung labu kuning dengan variasi lama perendaman menggunakan larutan natrium metabisulsit metabisulfit $1500 \mathrm{ppm}$

Berdasarkan uji organoleptik hedonik warna yang disukai oleh panelis dapat dilihat pada Gambar 8 bahwa semakin lama bahan direndam dalam larutan natrium metabisulfit maka warnanya semakin disukai, hal ini juga dinyatakan oleh Slamet (2010), dimana tepung yang diperoleh diberi perlakuan pendahuluan dengan perendaman dalam suatu larutan natrium metabisulfit memiliki warna lebih baik, hal ini dikarenakan oleh sulfit dapat menghalangi reaksi pada pencoklatan yang dikatalis oleh enzim fenolase dengan cara menonaktifkan reaksi pembentukan senyawa 5 hidroksil metal furfural dari D-glukosa penyebab terjadinya warna coklat. Tepung labu kuning pada perendaman 60 menit lebih cerah dari pada perendaman 0 menit. Warna tepung yang lebih bagus (cerah) akan menjadi daya tarik dan disukai oleh panelis. Warna pada tepung labu kuning sangat berpengaruh terhadap peningkatan daya tarik produk atau suatu bahan pangan.

\section{Organoleptik Hedonik Aroma}

. Pada Gambar 9 dapat dilihat uji organoleptik hedonik aroma tepung labu kuning berdasarkan perlakuan lama perendaman dalam natrium metabisulfit $1500 \mathrm{ppm}$.

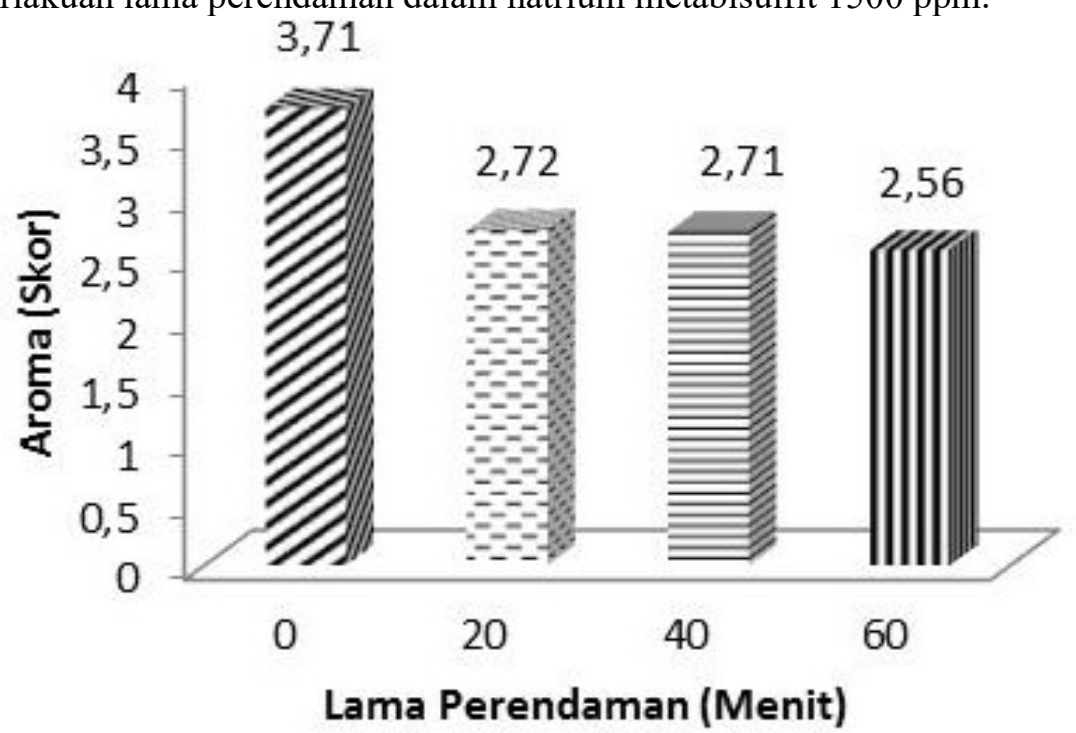

Jurnal Ilmiah Mahasiswa Pertanian, Volume 4, Nomor 3, Agustus 2019 
Gambar 9. Skor kesukaan terhadap aroma tepung labu kuning dengan variasi lama perendaman menggunakan larutan natrium metabisulfit $1500 \mathrm{ppm}$

Dari hasil uji organoleptik terhadap kesukaan aroma pada Gambar 10 menunjukkan bahwa skor tertinggi atau yang paling disukai oleh panelis diperoleh dari lama perendaman 0 menit dengan nilai rata-rata 3,71 dengan skor 4 (suka), dan hasil uji organoleptik terhadap kesukaan aroma menunjukkan skor terendah diperoleh dari lama perendaman 60 menit dengan nilai rata-rata 2,56 dengan nilai skor netral. Dari hasil analis sidik ragam (ANOVA) terhadap kadar air yang menjelaskan bahwasanya lama perendaman dalam larutan natrium metabisulfit $1500 \mathrm{ppm}$ dapat berpengaruh nyata hal ini dikarenakan nilai signifikan $<$ dari 0,05 terhadap kadar air tepung labu kuning sehingga perlu dilakukan uji lanjut.

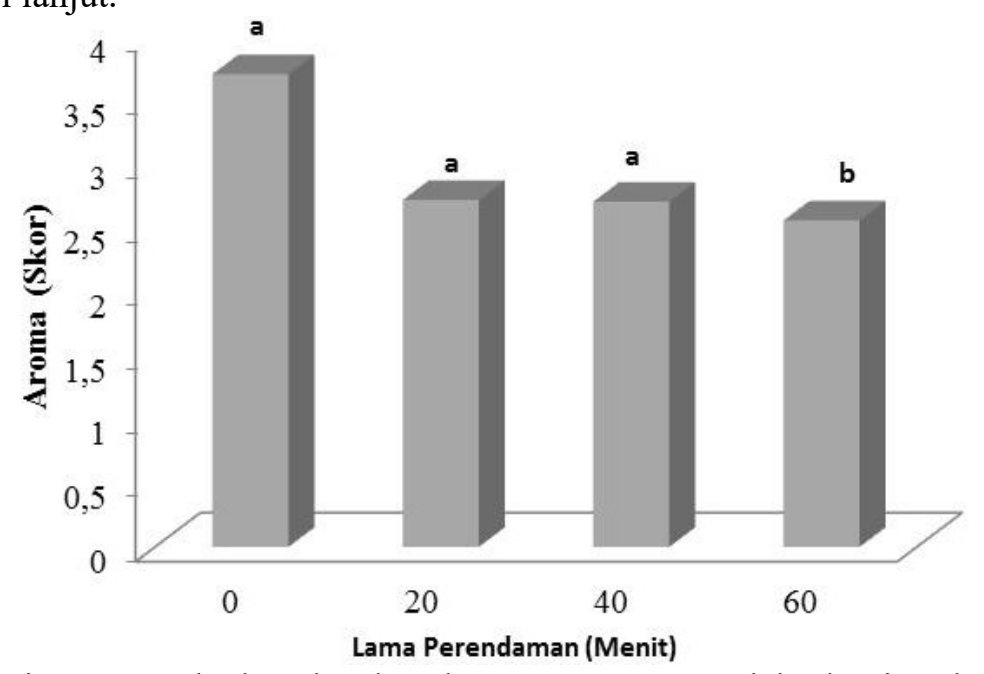

Gambar 10. Uji lanjut BNJ terhadap skor kesukaan aroma tepung labu kuning dengan variasi lama perendaman menggunakan larutan natrium metabisulsit metabisulfit $1500 \mathrm{ppm}$

Skor kesukaan terhadap aroma pada tepung labu kuning menunjukkan tingkat kesukaan panelis terhadap bahan dengan perlakuan lama perendaman dalam larutan natrium metabisulfit. Hasil dari uji organoleptik hedonik aroma terhadap kesukaan panelis memperoleh rerata 3 (Netral), hal ini disebabkan karena bau asli dari labu kuning masih tercium walaupun sudah dalam bentuk tepung labu kuning. Nilai skor terhadap kesukaan aroma tepung labu kuning dengan perlakuan 0 menit memilik nilai tertinggi oleh panelis, hal ini disebabkan karena aroma asli labu kuning tidak hilang maka aromanya masih aroma asli dari labu kuning hal ini menyebabkan panelis lebih memilih pada perendaman 0 menit atau tanpa di rendam dengan skor sangat suka (4). 


\section{SIMPULAN DAN SARAN}

\section{Simpulan}

Adapun dari hasil penelitian yang telah dilakukan dapat diambil beberapa kesimpulan, sebagai berikut:

1. Dari nilai ANOVA menjelaskan bahwa lama perendaman pada lautan natrium metabisulfit 1500 ppm berpengaruh tidak nyata pada rendemen dan kadar air untuk semua variasi lama perendaman dengan nilai tertinggi pada perendaman 20 menit dan 60 menit.

2. Dari nilai ANOVA menjelaskan bahwa pada perendaman suatu larutan natrium metabisulfit 1500 ppm dapat berpengaruh nyata pada derajat keasaman $(\mathrm{pH})$ dengan nilai paling tinggi sebesar 6,393\% pada perendaman 20 menit, dan kadar pati dengan nilai tertinggi sebesar 72,96\% pada perendaman 40 menit, uji organoleptik hedonik warna dengan nilai paling tinggi sebesar 4,20 pada perendaman 60 menit, dan uji organoleptik hedonik aroma dengan nilai tertinggi 3,71 dengan skala 4 (suka).

3. Dari nilai rata-rata waktu perendaman pada setiap perlakuan yang diperoleh dari hasil penelitian, lama perendaman yang baik dilakukan selama 20 menit.

\section{Saran}

Adapun saran yang dapat diberikan adalah perlu digunakan labu kuning dengan kematangan yang seragam agar diperoleh tepung labu kuning dengan kematangan yang seragam juga. 


\section{DAFTAR PUSTAKA}

BSN. 2009. Tepung terigu sebagai bahan makanan (SNI 3751:2009). Badan Standarisasi Nasional, Jakarta.

Dewi, A. R . 2017. Pengaruh variasi konsenterasi larutan natrium metabisulfit $\left(\mathrm{Na}_{2} \mathrm{~S}_{2} \mathrm{O}_{5}\right)$ pada perendaman biji alpukat terhadap mutu tepung biji alpukat. Skripsi. Program Studi Teknik Pertanian Fakultas Pertanian. Universitas Syiah Kuala, Banda Aceh.

Hendrasty, H.K. 2003. Tepung Labu Kuning Pembuatan dan Pemanfaatannya. Kanisius, Yogyakarta.

Hildayanti, R. 2005. Pengaruh lama perendaman natrium metabisulfit $\left(\mathrm{Na}_{2} \mathrm{~S}_{2} \mathrm{O}_{5}\right)$ dan lama pengeringan terhadap mutu tepung sukun (artocapus communis). Skripsi. Fakultas Pertanian. Universitas Sumatera Utara, Medan.

Montolalu, S., N. Lontaan, S. Sakul dan A. Dp. Mirah. 2013. Sifat fisiko-kimia dan mutu organoleptik bakso boiler dengan menggunakan tepung ubi jalar. Jurnal Zootek. 32(5). ISSN 0852-2626.

Slamet, A. 2010. Pengaruh perlakuan pendahuluan pada pembuatan tepung ganyong (canna Edulis) terhadap sifat fisik dan amilografi tepung yang dihasikan. Jurnal Agrointek 4(2) : 67-69.

Widya, D. 2003. Proses dan Karakteristik Tepung Biji Mangga Jenis Aromanis. Skripsi. Fakultas Teknologi Pertanian Institut Pertanian Bogor. Bogor.

Winarno. 2002. Kimia Pangan dan gizi. Gramedia Pustaka Utama, Jakarta. 